\title{
FARTLEK TRAINING LEBIH MENINGKATKAN DAYA TAHAN KARDIOVASKULER DARI PADA INTERVAL TRAINING PADA SISWA PUTRA PESERTA EKSTRAKURIKULER BOLA BASKET SMA NEGERI 1 SUKAWATI
}

\author{
Gusti Made Agung Mega Utama ${ }^{1}$, I Made Jawi², Ni Nyoman Ayu Dewi ${ }^{3}$, I Wayan Weta ${ }^{4}$, \\ Made Muliarta $^{5}$, I D A Inten Dwi Primayanti ${ }^{6}$ \\ ${ }^{1}$ Program Studi Magister Fisiologi Keolahragaan Universitas Udayana Denpasar Bali \\ 2,3,4,5,6Fakultas Kedokteran Universitas Udayana Denpasar Bali
}

\begin{abstract}
ABSTRAK
Bola basket adalah permainan bola besar yang memerlukan daya tahan kardiovaskular yang baik. Untuk meningkatkan daya tahan kardiovaskuler dapat dilakukan melaui interval training dan fartlek training. Tujuan dari penelitian ini untuk mencari perbandingan interval dan fartlek training terhadap peningkatan daya tahan kardiovaskuler. Penelitian ini adalah penelitian eksperimental dengan rancangan randomized pretest posttest control group design yang dilaksanakan pada SMA Negeri 1 Sukawati. Sampel penelitian adalah siswa putra peserta ekstrakurikuler bola basket SMA Negeri 1 Sukawati berjumlah 22 siswa, yang dibagi menjadi dua kelompok. Kedua kelompok diberikan pelatihan yang berbeda selama enam minggu dan frekuensi latihan tiga kali dalam satu minggu dalam satu setengah bulan. Kelompok 1 diberikan interval training dan kelompok 2 diberikan fartlek training. Daya tahan kardiovaskuler diukur dengan multistage fitness test (MFT). Hasil penelitian menunjukkan rerata daya tahan kardiovaskuler antar kelompok sesudah pelatihan sebesar $41.7 \pm 2.73 \mathrm{ml} / \mathrm{kg} / \mathrm{menit}$ pada kelompok interval training dan pada kelompok fartlek training sebesar $48.9 \pm 2.39 \mathrm{ml} / \mathrm{kg} / \mathrm{menit}$. Hasil uji $t$-independent antar kelompok dan t-paired antara kedua kelompok pelatihan sebelum dan sesudah, diperoleh hasil $\mathrm{p}=0,000$ pada masing- masing kelompok hal ini berarti nilai $\mathrm{p}$ lebih kecil dari 0,05 berarti masing-masing pelatihan berbeda, bermakna dan mengalami peningkatan. Kesimpulan dari penelitian ini adalah interval training dan fartlek training dapat meningkatkan daya tahan kardiovaskuler, di mana fartlek training lebih meningkatkan daya tahan kardiovaskuler dari pada interval training. Oleh karena itu, untuk meningkatkan daya tahan kardiovaskuler disarankan mempergunakan fartlek training.
\end{abstract}

Kata kunci : fartlek training, interval training, daya tahan kardiovaskuler

\section{FARTLEK TRAINING INCREASES CARDIOVASCULAR ENDURANCE BETTER INTERVAL TRAINING IN MALE BASKETBALL PLAYERS AT SMA NEGERI 1 SUKAWATI}

\begin{abstract}
Basketball is a big ball game that requires well cardiovascular endurance. Cardiovasculer endurance can be improved using interval training and fartlek training. This study aimed to determine the effect of interval training and fartlek training on cardiovascular endurance improvement. The study was a experimental that use randomized pretest posttest design group control that does in SMA Negeri 1 Sukawati. The sample of study was students of extracurricular basketball SMA Negeri 1 Sukawati, which were 22 students that divided into 2
\end{abstract}


groups. Both groups were given different training during 6 weeks with training frequency three times a week for one and a half months. The first group was given interval training and the second group was given fartlek training. Cardiovascular endurance was measured with a multistage fitness test (MFT). The result showed the mean of cardiovascular endurance between the groups after training was $41.66 \pm 2.733 \mathrm{ml} / \mathrm{kg} /$ minute in the interval training group and was $48.92 \pm 2.385 \mathrm{ml} / \mathrm{kg} /$ minute in the fartlek group. The cardiovascular endurance between both groups was significantly different $(\mathrm{p}<0.05)$, meaningful and have improvement. The conclusion is the interval training and fartlek training are able to improve cardiovascular endurance, however fartlek training is better than interval training in improving cardiovascular endurance. Therefore, it is advisable to use fartlek training to improve cardiovascular endurance for basketball players.

Keywords: cardiovascular endurance, fartlek training, interval training

\section{PENDAHULUAN}

Bola basket adalah permainan bola besar yang memerlukan daya tahan kardiovaskuler yang baik, karena pada umumnya permainan ini dimainkan dalam 4 quarter atau babak dimana dalam setiap quarter masing-masing 10 menit. Tipe permainan ini membutuhkan daya tahan yang baik. Tanpa memiliki ketahanan yang cukup bagus, sehingga pemain tidak mampu memainkan teknik dan taktik yang dimiliki dengan baik ${ }^{1}$. Pada SMAN. 1 Sukawati, masalah yang didapatkan adalah daya tahan kardiovaskuler yang kurang baik, itu dapat dilihat pada beberapa pertandingan yang diikuti baik di tingakat Kabupaten maupun Provinsi, atlet terlihat kelelahan pada akhirakhir permainan pada pertandingan tersebut, poin yang merekan peroleh merosot dari babak-babak sebelumnya yang disebabkan karena daya tahan kardiovaskuler menurun.

Kebugaran fisik adalah kesanggupan tubuh untuk melakukan berbagai aktivitas tanpa mengalami kelelahan berarti ${ }^{2}$. Peningkatan prestasi olahraga bisa dilakukan melalui pembibitan, pembinaan, pelatihan dan penelitian senantiasa dilakukan supaya mampu bersaing dalam setiap kejuaraan dan mampu menghasilkan prestasi secara maksimal.

Mengingat pentingnya daya tahan kardiovaskuler, perlu diberkan pelatihan yang terukur yaitu interval training dan fartlek training. Interval training adalah latihan yang memberikan jeda istirahat di sela-sela latihan yang dilakukan sedangkan fartlek trining merupakan salah satu latihan endurance yang sangat baik untuk mengembangkan, mengembalikan dan membangun daya tahan pada olahraga bola basket ${ }^{3}$. Melalui interval training dan fartlek training diharapkan supaya pemain bola basket tidak mudah mengalami kelelahan, cedera olahraga dan meningkatkan ketrampilan bermain serta untuk mengajarkan teknik pengambilan oksigen supaya mengefesienkan energi pada saat berlatih maupun bertanding. Otot yang terlibat dalam interval training adalah musculus gastrocnemius, musculus fibularis dan beberapa otot lengan seperti musculus biseps, musculus triceps brachii ${ }^{4}$. Otot yang terlibat dalam fartlek training adalah musculus gastrocnemius, soleus, rectus femoris, peroneus, biceps femoris dan tibialis anterior $^{3}$.

Salah satu keuntungan interval training dan fartlek training adalah memberikan pelatihan kepada atlet mengenai pengaturan tempo menetapkan langkah dan lebar dalam satuan waktu, disisi lain adalah membuat siswa lebih bersemangat menjalani proses pelatihan yang diberikan selama latihan $^{5}$.

Penelitian ini bertujuan untuk membuktikan bahwa interval training dan fartlek training dapat meningkatkan daya tahan kardiovaskuler. Manfaat yang diperoleh dalam penelitian ini yaitu sebagai pedoman 
bagi para pembina, pelatih, guru pjok dan atlet untuk peningkatan prestasi cabang olahraga khususnya yang membutuhkan daya tahan kardiovaskuler.

\section{METODE PENELITIAN Rancangan Penelitian}

Rancangan dalam penelitian ini adalah menggunakan Randomized Pretst-Posttest Control Group Design. Subyek penelitiannya adalah 22 orang siswa putra peserta ekstrakurikuler bola basket SMAN.1 Sukawati. Subyek dalam penelitian dibagi menjadi dua kelompok perlakuan masingmasing 11 orang subyek, yaitu perlakuan I (interval training) dan perlakuan II (fartlek training).

\section{Waktu dan Lokasi Penelitian}

Penelitian ini dilaksanakan di lapangan SMAN.1 Sukawati, Kabupaten Gianyar dimana waktu penelitian dilaksanakan selama enam minggu dan frekuensi latihan 3 kali dalam seminggu, yaitu pada hari Selasa, Kamis dan Minggu mulai pukul 16.00 WITA hingga selesai.

\section{Populasi dan Sampel}

Populasi penelitian adalah seluruh siswa putra peserta ekstrakurikuler bola basket SMAN. 1 Sukawati. Sampel penelitian ini diambil dari populasi yang telah memenuhi kriteria inklusi dan eksklusi.

Sampel penelitian ini diambil dari populasi terjangkau yang memenuhi kriteria inklusi : 1 . Kriteria inklusi dalam penelitian ini adalah: Siswa putra berusia 16-18 tahun, sehat jasmani dan rohani, melakukan olahraga minimal 2x seminggu, bersedia menjadi sampel dalam penelitian ini sampai selesai. 2 . Kriteria eksklusi dalam penelitian ini adalah : Mempunyai riwayat cedera dan sakit sesaat sebelum penelitian yang diukur dengan cara melakukan wawancara terhadap sampel.

\section{Pengukuran Daya Tahan Kardiovaskuler}

Daya tahan kardiovaskuler diukur dengan Multistage Fitnes Test (MFT) yaitu subyek berlari bolak-balik dengan jarak 20 meter dengan mendengarkan bunyi "TUT" pencapaian setiap titiknya sesuai dengan kemampuan tanpa henti. Capaian dicatat kemudian dikonversikan dengan tabel prediksi nilai ambilan oksigen maksimum dengan tes lari multi tahap. Acuan pengukuran $M F T$ mempergunakan tabel standar tes lari multi tahap.

\section{HASIL PENELITIAN \\ Karakteristi Subjek Penelitian}

Karakteristik subyek dalam penelitian ini adalah: umur, berat badan, tinggi badan, kebugaran fisik.

Tabel 1

Karakteristik Subyek Penelitian

\begin{tabular}{lcc}
\hline \multirow{2}{*}{$\begin{array}{c}\text { Karakteristik } \\
\text { subyek }\end{array}$} & \multicolumn{2}{c}{ Rerata \pm SB } \\
\cline { 2 - 3 } & Kelompok 1 & Kelompok 2 \\
\hline $\begin{array}{l}\text { Umur (th) } \\
\begin{array}{l}\text { Berat Badan } \\
\text { (kg) }\end{array}\end{array}$ & $16,36 \pm 0,51$ & $16,27 \pm 0,47$ \\
$\begin{array}{l}\text { Tinggi Badan } \\
\text { (cm) }\end{array}$ & $67,64 \pm 7,35$ & $67,00 \pm 7,54$ \\
$\begin{array}{l}\text { Kebugaran } \\
\text { Fisik (menit) }\end{array}$ & $11,36 \pm 0,59$ & $11,17 \pm 0,64$ \\
\hline
\end{tabular}

\section{Karakteristik Lingkungan Penelitian}

Kondisi lingkungan dalam penelitian yang diukur selama 18 kali penelitian yaitu sebanyak tiga kali seminggu selama enam minggu adalah suhu dan kelembaban udara tempat penelitian dilakukan seperti tabel 2

Tabel 2

Data Suhu dan Kelembaban Lingkungan

Penelitian

\begin{tabular}{lccc}
\hline $\begin{array}{c}\text { Keadaan } \\
\text { Lingkungan }\end{array}$ & Minimum & Maksimum & $\begin{array}{c}\text { Rerata } \pm \\
\text { SB }\end{array}$ \\
\hline Suhu $\left({ }^{\circ} \mathrm{C}\right)$ & 28,00 & 30,00 & $\begin{array}{c}29,09 \pm \\
0,55\end{array}$ \\
$\begin{array}{lccc}\text { Kelembaban } \\
(\%)\end{array}$ & 67 & 79 & $73,33 \pm$ \\
\end{tabular}

\section{Uji Normalitas dan Homogenitas}

Untuk mengetahui distribusi sampel penelitian, dilakukan uji normalitas dengan menggunakan Saphiro Wilk Test. Sedangkan 
uji homogenitas menggunakan Levene test

Tabel 3

Hasil Uji Normalitas dan Homogenitas Data Hasil Daya Tahan Kardiovaskuler Sebelum dan Sesudah Pelatihan

\begin{tabular}{|c|c|c|c|}
\hline \multirow[t]{2}{*}{ Variabel } & \multicolumn{2}{|c|}{$\begin{array}{c}\text { Uji Normalitas (Shapiro- } \\
\text { Wilk Test) } \\
\text { P }\end{array}$} & \multirow{2}{*}{$\begin{array}{c}\text { Homogenitas } \\
\mathrm{P} \\
\text { (Levene Test) }\end{array}$} \\
\hline & $\begin{array}{c}\text { Kelompok } \\
1 \\
\end{array}$ & $\begin{array}{c}\text { Kelompok } \\
2 \\
\end{array}$ & \\
\hline Pre test & 0,337 & 0,515 & 0,309 \\
\hline Post test & 0,101 & 0,087 & 0,909 \\
\hline
\end{tabular}

Tabel 3 menunjukkan data berdistribusi normal dan homogenitas, data daya tahan kardiovaskuler sebelum dan sesudah pelatihan, didapat kedua kelompok pelatihan memiliki nilai $\mathrm{p}$ mebih besar dari 0,05 yang berarti data daya tahan kardiovaskuler yang dilakukan sebelum dan setelah pelatihan berdistribusi normal dan homogen sehingga uji dilanjutkan dengan menggunakan uji parametrik.

Untuk mengetahui perbedaan hasil daya tahan kardiovaskuler antara sebelum dan sesudah pelatihan digunakan uji t-paired (tberpasangan) dan uji t-independent test ( $\mathrm{t}-$ tidak berpasangan) untuk membandingkan rerata hasil daya tahan kardiovaskuler antara kedua kelompok sebelum atau sesudah pelatihan pada batas kemaknaan $\alpha=0,05$ yang hasilnya disajikan pada tabel 4 .

Tabel 4

Uji Beda Rerata Hasil Dya Tahan Kardiovaskuler Antara Sebelum dan Sesudah Pelatihan Pada Kelompok 1 dan Kelompok 2

\begin{tabular}{|c|c|c|c|}
\hline \multirow[t]{2}{*}{ Kelompok } & \multicolumn{2}{|c|}{$\begin{array}{l}\text { Daya Tahan Kardiovaskuler } \\
\text { (ml/kg/menit) }\end{array}$} & \multirow[t]{2}{*}{$\mathrm{p}^{*}$} \\
\hline & $\begin{array}{c}\text { Sebelum } \\
\text { Pelatihan } \\
(\text { Rerata } \pm \text { SB ) }\end{array}$ & $\begin{array}{c}\text { Sesudah } \\
\text { Pelatihan } \\
(\text { Rerata } \pm \text { SB } \\
\text { ) }\end{array}$ & \\
\hline 1 & $28,6 \pm 0,87$ & $41,7 \pm 2,73$ & 0,000 \\
\hline 2 & $29,1 \pm 0,71$ & $48,9 \pm 2,39$ & 0,000 \\
\hline
\end{tabular}

$\mathrm{p}^{* *}$

0,187

0,000
Tabel 4 menunjukkan bahwa hasil rerata daya tahan kardiovaskuler antara sebelum dan sesudah pelatihan pada masingmasing kelompok dengan menggunakan uji $t$ paired (berpasangan) dengan nilai $\mathrm{p}=0,000$ pada masing-masing kelompok. Ini berarti bahwa pada masing-masing kelompok terjadi perbedaan hasil daya tahan kardiovaskuler antara sebelum dan sesudah pelatihan yang secara statistik berbeda bermakna.

Tabel 4 menunjukkan bahwa rerata hasil daya tahan kardiovaskuler sebelum pelatihan pada kedua kelompok dengan menggunkan uji t-independent (t-tidak berpasangan) dengan nilai $\mathrm{p}=0,0187$. Ini berarti rerata hasil daya tahan kardiovaskuler sebelum pelatihan antar kedua kelompok tidak berbeda bermakna.

Tabel 4 menunjukkan bahwa rerata hasil daya tahan kardiovaskuler sesudah pelatihan pada kedua kelompok dengan menggunakan uji t-independent (t-tidak berpasangan) dengan nilai $\mathrm{p}=0,000$. Ini berarti rerata hasil daya tahan kardiovaskuler sesudah pelatihan antar kedua kelompok berbeda bermakna. Perbedaan hasil daya tahan kardiovaskuler sesudah pelatihan disebabkan oleh perbedaan jenis pelatihan yang diberikan.

\section{PEMBAHASAN}

Daya tahan sangat erat kaitannya dengan durasi, lama latihan dan intensitas; semakin lama durasi dan intensitas latihan yang bisa dilakukan oleh seorang olahragawan, berarti ia mempunyai ketahanan atau daya tahan baik ${ }^{6}$. Kardiovaskuler adalah kemampuan seseorang mempergunakan sistem jantung, paru dan pembuluh darahnya untuk berfungsi secara efektif dan efesien pada keadaan istirahat dan latihan secara terus menerus dalam upaya mengeluarkan dan mengambil oksigen sehingga dapat digunakan dalam proses metabolisme tubuh ${ }^{7}$.

Pelatihan fisik diberikan secara teratur dengan takaran yang tepat dan frekuensi yang cukup, bisa menyebabkan 
fungsi tubuh akan berubah terhadap peningkatan kemampuan memproduksi tenaga serta memberikan perubahan pada kemampuan fisiknya. Latihan fisik yang dilakukan secara cepat dan kuat, akan menghasilkan peningkatan terhadap ATP, glikogen maupun keratin, seluruh proses ini dikenal dengan nama glikolisis aerobik ${ }^{8}$. Meningkatnya intensitas pelatihan bisa meningkatkan konsumsi oksigen maksimal serta menyebabkan terjadinya proses plateu. Dimana proses tersebut menunjukkan bahwa atlet tersebut berada pada batas maksimal, ini juga bisa menyebabkan kelelahan, nyeri pada dada, ini dikarenakan tubuh tidak mendapatkan suplai oksigen yang maksimal pada saat latihan, dapat disimpulkan bahwa VO2Max dapat membatasi aktivitas pada saat melaksanakan pelatihan fisik ${ }^{9}$.

Interval training memberikan efek fisiologis pada sistem kardiovaskuler yaitu otot pada jantung akan bertambah besar dan kuat, karena pelatihan yang diberikan berupa jogging dan jalan 50 meter selama 5 repetisi 3 set dimana waktu setiap repetisinya adalah 2 menit. Peningkatan dari jumlah darah yang dipompakan oleh jantung pada setiap denyutannya akan menjadi meningkat, ini disebabkan pelatihan yang diberikan memberikan efek pada bertambah kuat dan besarnya otot jantung. Pembuluh darah juga meningkat dan menyebabkan jumlah darah yang dialirkan akan juga akan menaingkat. Meningkatnya sistem dari kardiovaskuler tersebut meningkatkan jumlah aliran darah yang dialirkan kesemua jaringan lebih banyak dan juga oksigen yang dibawa darah dan jumlah hemoglobin akan bertambah banyak dimana pasokan oksigen kepada organ lainnya terpenuhi sendirinya dimana organ tersebut bisa berjalan sesuai dengan fungsinya dengan baik $^{3}$.

Fartlek training memberikan efek fisiologis pada sistem kardiovaskuler yaitu dimana pelatihan ini bukan hanya meningkatkan daya tahan kardiovaskuler tetapi juga meningkatkan kondisi fisik yang lain seperti kelincahan, kekuatan, daya tahan dan muscular power dan koordinasi karena dalam fartlek training bentuk latihannya bervariasi, dimana bentuk pelatihannya berupa jogging, jalan 50 meter dan melompati 5 buah kun secara kontinyu selama 30 menit. Sehingga mengakibatkan jantung bekerja lebih maksimal sehingga terjadi adaptasi jantung dan peredaran darah. Selain itu pada saat lari terus menerus, energi yang lebih banyak diperlukan adalah aerobik yaitu bantuan dari oksigen sehingga pada saat fartlek training berlangsung memerlukan oksigen yang lebih banyak di otot yang aktif. Jumlah darah keluar yang dipompakan oleh jantung mengakibatkan otot jantung mengalami penambahan beban pada jantung menjadi besar. Dimana proses tersebut merupakan stimulus atau pacuan yang mengakibatkan otot jantung lebih efesien dan kuat. Dengan pelatihan fartlek training yang gerakannya bervariasi mengakibatkan proses adaptasi terhadap otot jantung dimana mengakibatkan daya tahan kardiovaskuler meningkat dengan baik ${ }^{10}$.

Hasil yang mendukung penelitian ini adalah penelitian yang dilakukan ${ }^{3}$, bahwa fartlek training lebih baik dari pada interval training dalam meningkatkan daya tahan kardiovaskuler. Penelitian ini didukung oleh penelitian yang dilakukan ${ }^{11}$, terhadap 22 subjek dengan pelatihan fartlek dan pelatihan jogging, bahwa semua tipe pelatihan dapat meningkatkan VO2Max, dan fartlek training lebih baik daripada jogging.

Perbedaan jenis gerakan yang diberikan memberikan efek perbedaan terhadap pembentukan kemampuan daya tahan terhadap subyek yang diberikan pelatihan. Kelompok yang diberikan interval training dan fartlek training memiliki pengaruh yang berbeda terhadap peningkatan daya tahan kardiovaskuler, dimana repetisi dan set dalam pelatihan sudah dibuat sama.

\section{KESIMPULAN DAN SARAN}

Berdasarkan uraian dan hasil dari penelitian yang dilakukan, ditarik disimpulkan adalah interval training dan fartlek training dapat meningkatkan daya tahan kardiovaskuler. Fartlek training lebih 
efektif dalam meningkatkan daya tahan kardiovaskuler dari pada interval training.

Berdasarkan hasil dari penelitian ini dapat disarankan kepada pelatih, guru dan pembina olahraga agar bisa menggunakan fartlek training untuk meningkatkan daya tahan kardiovaskuler.

\section{DAFTAR PUSTAKA}

1. PERBASI, 2005. Peraturan Permainan Bola Basket. Jakarta: PB PERBASI.

2. Depdiknas. (2003). Pusat Kebugaran dan Rekreasi. Jakarta: Depdikbud.

3. Indrayana, B. 2012. Perbedaan pengaruh latihan interval training dan fartlek terhadap daya tahan kardiovaskuler pada atlet junior putra taekwondo. Cerdas sifa, edisi no.1 Mei-Agustus.

4. Sanjaya, I.G.B., Yoda, I.K., Sudarmada, I.N. 2016. Pengaruh Pelatihan Running Interval 30 Meter Dengan Rasio Kerja Istirahat 1:3 Dan 1:5 Peningkatan Kardiovaskuler. e-Journal IKOR Universitas Pendidikan Ganesha Jurusan Ilmu keolahragaan, Volume 1, Tahun 2016.

5. Aisyah, K.D. 2015. Pengaruh Latihan Rope Jump Dengan Metode Interval Training Terhadap Kekuatan Otot Tungkai. Jurnal Kesehatan Olahraga Volume 03 Nomor 01 Tahun 2015, 79-86.

6. Sukadiyanto. 2011. Pengantar Teori dan Metodologi Melatih Fisik. Yogyakarta: Pendidikan Kepelatihan Olahraga FIK Universitas Negeri Yogyakarta.

7. Adiatmika, I.P.G. 2002. Pemeriksaan Kebugaran Jasmani. Denpasar: Universitas Udayana.

8. McArdle, W.D., Katch, F.I., Katch. V. L. 2010. Exercise Physiology: Nutrition, Energy, and Human Performance. Seventh Edition. Hiladelphi: Lippincott Williams and wilkins : 500-506.

9. Wilmore, J.H., Castil, 2005. Training For Sport and Activity. Win C. "Brown Publisher, Dubuque. Lowa.
10. Kurnia, M. 2013. Pengaruh Latihan Fartlek Dengan Treadmill Dan Lari Di Lapangan Terhadap Daya Tahan Kardiorespirasi. Jurnal Keolahragaan Tahun 2013. Volume 1. Nomor 1.

11. Herta, I.K. 2016. Pengaruh Fartlek Dan Jogging Terhadap Peningkatan VO2Max Tim Sepakbola SMAN 1 Kotagajah. Jurnal Pendidikan Jasmani Kesehatan Dan Rekreasi FKIP UNILA. Mei 2 
